\title{
Animal models for the atherosclerosis research: a review
}

\author{
Xiangdong Li ${ }^{\bowtie}$, Yuanwu Liu, Hua Zhang, Liming Ren, Qiuyan Li, Ning Li ${ }^{\bowtie}$ \\ State Key Laboratory of Agrobiotechnology, China Agricultural University, Beijing 100193, China \\ $\bowtie$ Correspondence: xiangdongli@cau.edu.cn (X. Li),ninglcau@cau.edu.cn (N. Li) \\ Received January 22, 2011 Accepted January 30, 2011
}

\begin{abstract}
Atherosclerosis is a leading cause of death worldwide, and its mechanisms are still unclear. However, various animal models have significantly advanced our understanding of the mechanisms involved in atherosclerosis and have allowed the evaluation of therapeutic options. The aim of this paper is to review those animal models (i.e., rabbits, mice, rats, guinea pigs, hamsters, avian, carnivores, swine, and, non-human primates) that have been used to study atherosclerosis. Though there is no single perfect animal model that completely replicates the stages of human atherosclerosis, cholesterol feeding and mechanical endothelial injury are two common features shared by most models of atherosclerosis. Further, with the development of genetically modified animals, these models are significantly broadening our understanding of the pathogenesis of atherosclerosis.
\end{abstract}

\section{KEYWORDS animal model, atherosclerosis}

\section{ATHEROSCLEROSIS DEFINITION, EPIDEMIOLOGICAL EVIDENCE, AND EXISTING MECHANISMS}

Atherosclerosis is a clinic condition in which an artery wall thickens as a result of the build-up of fatty materials, cholesterol, macrophages, cellular waste products, calcium and other substance, which can grow large enough to significantly reduce blood flow through the affected artery. Atherosclerosis contributes to the most frequent underlying cause of coronary artery disease, carotid artery disease, and peripheral vascular disease, which cumulatively are the leading cause of mortality worldwide (Association, 2010; Organization, 2011). In recent years, various hypotheses regarding the pathogenesis of this clinical condition have been published and been reviewed elsewhere (Glass and Witztum, 2001).

Briefly, high plasma low-density lipoprotein (LDL) cholesterol concentrations, especially oxidized LDL (oxLDL) (Ross, 1993; Glass and Witztum, 2001; Libby and Aikawa, 2002), initiate formation of the atherosclerotic lesion (Ross, 1993). After initiation, endothelial cells express various adhesion molecules, leading to the attachment of leucocytes to the endothelium. Adhesion molecules such as vascular cell adhesion molecule-1 (VCAM-1), intercellular adhesion molecule-1 (ICAM-1), and E-selectins play major roles in binding, particularly of monocytes and T-lymphocytes, the main cell types found at early atherosclerotic lesions. After their adhesion to endothelial cells, monocytes migrate to the sub-endothelial space, where they differentiate into macrophages. Macrophages express scavenger receptors and take up the cholesterol and oxLDL, subsequently developing into lipid-rich foam cells. The accumulation of foam cells results in the formation of fatty streaks within the vessel wall. These foam cells produce cytokines and reactive oxygen species, which enhance the inflammatory process.

As the process continues, smooth muscle cells immigrate from the medial layer into the intimal or sub-endothelial space where they may proliferate, ingest modified lipoproteins, and contribute to more complex lesions as smooth muscle cells secrete extracellular matrix proteins, leading to the development of fibrous plaque (Ross, 1999). This phase of the lesion is influenced by a broad range of cellular and humoral responses, such as a chronic inflammatory state (Hansson, 2005, 2009), resulting in the narrowing of the aortic lumen. Advanced lesions occur with rupture of the plaque, which allows blood components to come in contact with plaque lipids and tissue factor, resulting in the formation of a thrombus and leading to ischemic 


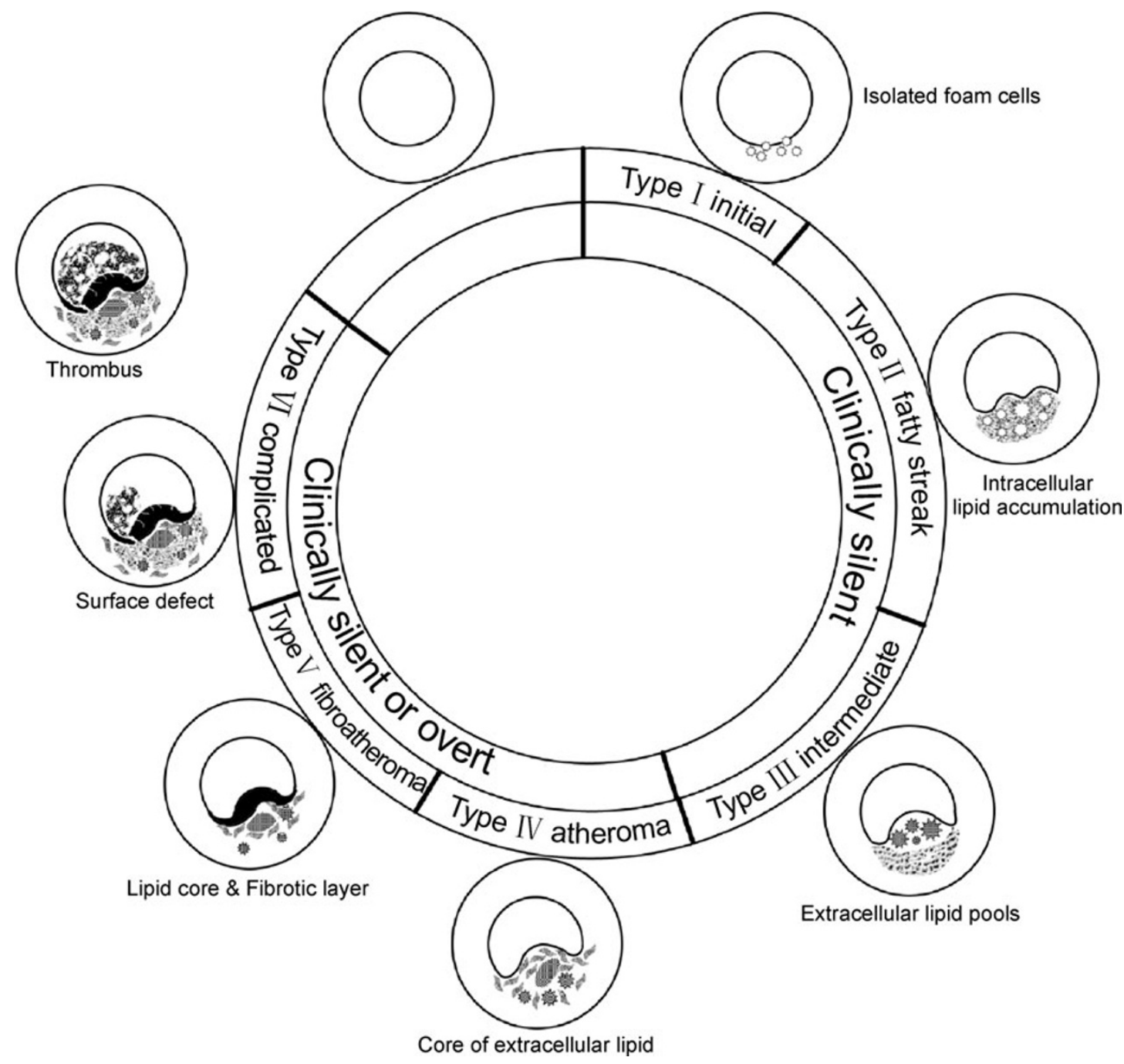

Figure 1. Pathology of atherosclerotic disease. Classification of the six types of artery wall lesion, modified from Stary et al. (1995).

symptoms such as myocardial infarction and stroke (Fig. 1) (Davies and Hollman, 1998; Libby and Aikawa, 2002).

While atherosclerosis is a multifactorial disease involving a number of genetic and environmental factors, the most common risk factor for the development of this disease is the alteration of cholesterol levels in the blood. For the past two decades, the statin class of cholesterol-lowering drugs has been the first-line therapy for the treatment of hypercholesterolemia (Knopp, 1999; Knopp and Paramsothy, 2006). Despite their efficacy in lowering cholesterol levels and reducing cardiovascular causes of death, $70 \%$ of statintreated patients still experience adverse coronary events (Mohrschladt et al., 2004). Thus, there has been a significant push toward the development of new therapeutics that target risk factors other than hypercholesterolemia, and that can be used alone or in combination with a statin.

Animal models that help to elucidate the pathogenetic steps and causalities in atherosclerosis play a crucial role in the current search for new therapeutics. A milestone study was published in 1908 when the Russian scientist Alexander Ignatowski demonstrated that atherosclerosis can be induced in rabbits by feeding them milk and egg yolks (Ignatowski, 1908). Since then, animal models (including mice, rats, guinea pigs, hamsters, avian, swine, and non-human primates) have provided valuable information about diagnostic and therapeutic strategies for atherosclerosis, with extensive investigation of events occurring in the artery wall throughout the course of the disease. This minireview provides information on the advantages and disadvantages of each model organism for atherosclerosis research. 


\section{ANIMAL MODELS OF ATHEROSCLEROSIS}

\section{Glires}

The Glires is a clade consisting of rodents (e.g., mice, rats, hamsters, and guinea pigs) and lagomorphs (e.g., rabbits, hares, and pikas). It should be noted, however, that rabbits are sometimes confused with rodents. In any event, rodents and rabbits are the most commonly used animals for atherosclerosis research.

\section{Rabbits}

After the first report of diet-induced atherosclerosis in rabbits by Ignatowski (Ignatowski, 1908) and the subsequent discovery that cholesterol-feeding induces atherosclerosis in rabbits by Chalatov (Anitschkow and Chalatow, 1913), atheromatic lesions were mainly introduced into rabbits by applying specific diets. Further, among all strains, New Zealand rabbits (with body weights between 2 and $5 \mathrm{~kg}$ ) are the most popular strain used for atherosclerosis research. More specifically, the Watanabe, St. Tomas, and Houston RT lines are the most important and widely used for study among the New Zealand rabbits (Watanabe, 1980; Kita et al., 1987; Armstrong and Heistad, 1990).

Several characteristics of the rabbit make it an excellent model for the study of atherosclerosis, including ease in maintaining and handling the animals, as well as their inexpensive upkeep and ready availability. The normal range of plasma cholesterol in the New Zealand white rabbit is low (average $=1.3 \mathrm{mmol} / \mathrm{L}$ ) (Finking and Hanke, 1997), but plasma cholesterol can increase two- to eight-fold within the first 20 days after the administration of a cholesterol-rich diet (Bocan et al., 1993). The atherosclerotic lesions are characterized by an increase in leukocyte immigration, endothelial penetration, and the formation of macrophagederived foam cells in the intima of the large conduit arteries (especially the aortic arch and thoracic aorta), which are similar to human fatty streaks at the early stage of the lesions.

The rabbit has been widely used and thoroughly reviewed as an atherogenesis model (Yanni et al., 2003). Indeed, different amounts of cholesterol in the diet (Bocan et al., 1993; Kolodgie et al., 1996), with or without a combination of oils (Kolodgie et al., 1996; Yanni et al., 2003) and specific proteins (Kritchevsky et al., 1977; West et al., 1982; Kritchevsky, 1995), as well as various durations of experimental studies (Hunt and Duncan, 1985; Rogers and Karnovsky, 1988), have been used to cause different types of lesions in arteries. A long-duration, low-cholesterol diet causes atherosclerotic lesions with smooth muscle cell penetration and cholesterol deposition, which are similar to that observed in human lesions (Kolodgie et al., 1996). In contrast, advanced atheromatic lesions are induced with casein,
$0.2 \%$ cholesterol, and $19 \%$ butterfat provided for 6 months to 5 years (Cornhill and Roach, 1974, 1976; Adams et al., 1982; West et al., 1982; Rogers and Karnovsky, 1988); some studies suggest that the formation of advanced lesions depends on the age of the animal. It was suggested that age is also a critical factor for the lesions, with 3- to 4.5-yearold rabbits exhibiting fibrotic plaques while young rabbits (4 months) do not (Spagnoli et al., 1991). To induce more advanced lesions, such as a fibrous cap with a high amount of smooth muscle cells in the thoracic and abdominal aorta, a high cholesterol diet must be combined with a single or double balloon injury (Abela et al., 1995; Aikawa et al., 1998; Worthley et al., 2000). Additionally, pharmacological triggering in combination with balloon injury results in the formation of plaques that are similar to those found in human coronary arteries (Johnstone et al., 2001).

The generation of genetically altered rabbits in recent years has extensively expanded our understanding of the mechanisms involved in the pathogenesis of atherosclerosis. The lipoprotein disorder rabbit models of familial hypercholesterolemia and familial combined hyperlipidemia (e.g., the St. Thomas' Hospital strains, Watanabe Heritable Hyperlipidemic (WHHL) (a genetic deprivation of functional LDL receptors) (Watanabe, 1980), and Houston RT (Armstrong and Heistad, 1990)) enable the assessment of candidate genes for potential use in the treatment of dyslipoproteinemic patients. In these animals, the atherosclerotic process begins in utero (Aliev and Burnstock, 1998), and the lesions progress with age. Indeed, atherosclerosis occurs even when these rabbits are fed a cholesterol free diet, and this is the same genetic defect seen in patients with familial hypercholesterolemia.

The use of transgenic rabbit models for the elucidation of the mechanisms of atherogenesis provides new insight of great interest. In 1993, Hoeg et al. (Hoeg et al., 1993) generated transgenic rabbits overexpressing human apolipoprotein (apo) A-I and these animals displayed significant decreases in atherosclerotic lesion areas compared to the control group (Duverger et al., 1996). In 1994, Fan and coworkers generated transgenic rabbits overexpressing human hepatic lipase (Fan et al., 1994), and the susceptibility of these rabbits to atherosclerosis has been determined (Taylor and Fan, 1997). In 1996, Hoeg et al. demonstrated that transgenic rabbits overexpressing human lecithin-cholesterol acyl transferase (LCAT) have markedly reduced atherosclerosis when fed a high cholesterol diet (Hoeg et al., 1996). Analysis of the plasma lipid concentration in human apoB-100 transgenic rabbits has revealed that total plasma cholesterol and triglyceride levels are two- to three-fold higher than those observed in age-, sex- and diet-matched, nontransgenic littermates (Fan et al., 1995; Brousseau and Hoeg, 1999). However, the levels of high-density lipoprotein (HDL) cholesterol are markedly reduced. The overexpression of lipoprotein lipase (LPL) in transgenic rabbits influences all 
classes of lipoproteins. These rabbits are highly resistant to diet-induced hypercholesterolemia and atherosclerosis (Fan et al., 2001b). In 1996, Shen and co-workers revealed that the overexpression of 15-lipoxygenase in monocytes/macrophages protects against lipid deposition in the vessel wall during early atherogenesis (Shen et al., 1996). Transgenic WHHL rabbits that express human apoA display more extensive advanced atherosclerotic lesions (e.g., atheroma, fibroatheroma, and calcification) compared to controls and a significant increase in the area of sudanophilic lesions in a diet-induced study (Fan et al., 2001a).

There are several disadvantages that limit the use of rabbits for studying the mechanisms of atherosclerosis. First, it is rare for rabbits to develop advanced lesions with fibrosis, hemorrhage, ulceration, and/or thrombosis, all characteristics of lesions in humans. Although the early lesions of fatty streaks are similar to those in humans, tissue plaques do not develop in the rabbit endothelium, which is a trademark of atherosclerosis in humans (Kolodgie et al., 1996). Second, in the rabbit, lesions are distributed predominantly in the aortic arch and thoracic aorta, at the origins of intercostal arteries, and (to a lesser extent) in the abdominal aorta. In humans, plaques are more abundant in the abdominal aorta enriched with smooth muscle cells and usually have a fibrous cap (Taylor and Fan, 1997). Third, a long-term, high cholesterol diet is highly hepatotoxic for the rabbits, which often causes mortality before the end of the study. Fourth, massive inflammation occurs in the body, which does not reflect the pathophysiology in human counterparts. Fifth, the majority of circulating cholesterol in rabbits is transported in HDL (Fig. 2), while the majority of circulating cholesterol in human is transported in LDL. Finally, antibodies needed to study the pathways involved in inflammation in rabbits are generally not available (Table 1).

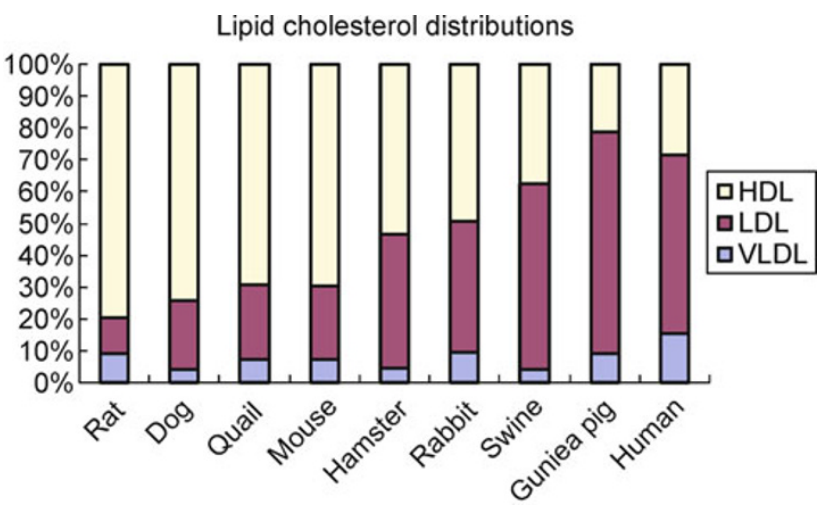

Figure 2. Comparisons between lipoprotein cholesterol distribution between several animal models and humans (Fernandez et al., 1999; Ramaswamy et al., 1999; Fernandez and Volek, 2006). HDL, high-density lipoprotein; LDL, lowdensity lipoprotein; VLDL, very low-density lipoprotein.
Mice

Generally, mice are resistant to diet-induced atherogenesis. Approximately $70 \%$ of the total plasma cholesterol is $\mathrm{HDL}$ particles in mice (Fig. 2) (Fernandez et al., 1999), which may be due to the lack of the plasma cholesteryl ester transfer protein (CETP). However, due to the hundreds of wellestablished inbred mouse lines, well-defined genetic map, and easily obtainable congenic and recombinant strains, the mouse model is currently the most widely used system to study atherosclerosis despite the anti-atherogenesis phenomenon.

A thorough study demonstrated that early stages of atherosclerotic lesions, such as fatty streaks, can be induced by means of atherogenic diets in C57BL/6J mice after comparison among 10 inbred strains which were fed a diet containing $1.25 \%(w / w)$ cholesterol, $0.5 \%(w / w)$ cholic acid, and $15 \%(w / w)$ fat (Nishina et al., 1990). In particular, when these animals are fed a very high cholesterol, high-fat diet supplemented with cholic acid for many months, several layers of foam cells appear in the subendothelial space (Breslow, 1996). Even the total serum cholesterol levels in all ten strains were increased, while plasma triglycerides increased in only three of the 10 and decreased in the other seven strains. More interestingly, atherogenesis was only observed in the AKR/J, DBA/2J, C57L/J, and C57BL/6J strains (Paigen et al., 1985), which caused difficulties in correlating total plasma cholesterol levels and atherogenesis (Paigen et al., 1985). It is strongly suggested that the animals' genetic background may play a significant role in their susceptibility to atherogenesis.

For many years, wild-type mice limited their widespread use in atherosclerotic research. However, unlike their wildtype counterparts, transgenic mice provide an excellent tool to study the interactions of gene(s) and the environment in atherogenesis. The mouse apoE gene was the first mouse gene successfully deleted for atherosclerosis research (Plump et al., 1992; Zhang et al., 1992). Later, several other relevant transgenic murine models, such as LDL receptorknockout (KO) (Véniant et al., 1998), hepatic lipase-KO (Mezdour et al., 1997), human apoB100 expression (PurcellHuynh et al., 1995), and human CETP expression (Marotti et al., 1993), were also developed. Thus far, 239 strains for atherosclerosis research have been published on the Jax Laboratory webpage. Among them, apoE-KO, LDL receptor$\mathrm{KO}$, and human apoB100 transgenic mice display marked atherogenesis throughout their arterial tree.

In particular, when these animals are fed a very high cholesterol, high-fat diet supplemented with cholic acid for many months, several layers of foam cells appear in the subendothelial space (Breslow, 1996). As one of the most extensively used models in atherosclerosis studies, the atherosclerotic lesions in apoE-KO mice have several characteristic features of human atheromas. These mice 
Table 1 Advantages and disadvantages of certain animal species in human atherosclerosis research

\begin{tabular}{|c|c|c|}
\hline Animals & Advantages & Disadvantages \\
\hline Rabbits & $\begin{array}{l}\text { Naturally LDL-receptor-deficient strain, naturally } \\
\text { hypertriglyceridemic strain, good size, easy to keep } \\
\text { and handle, known to many investigators, good } \\
\text { response to dietary cholesterol, and availability of } \\
\text { transgenic lines }\end{array}$ & $\begin{array}{l}\text { Lesion locations less similar to those in man, the majority of } \\
\text { circulating cholesterol is HDL, very high plasma cholesterol } \\
\text { needed to induce atherosclerosis, no advanced lesions, } \\
\text { hepatic lipase deficient, no spontaneous atherosclerosis, and } \\
\text { cholesterol storage syndrome on cholesterol feeding }\end{array}$ \\
\hline Mice & $\begin{array}{l}\text { Well-defined genetics, easy breeding, short generation } \\
\text { time, inbred availability, easy handling and housing, and } \\
\text { availability of several transgenic lines }\end{array}$ & $\begin{array}{l}\text { Highly resistant to atherogenesis, high HDL, no CETP, and } \\
\text { difficulties in frequent blood sampling and dissection of } \\
\text { medium/small-size vessels }\end{array}$ \\
\hline Rats & $\begin{array}{l}\text { Easy handling and housing, several strains of rats with } \\
\text { heritable hyperlipidemia (some of which are associated } \\
\text { with atherogenesis), and transgenic rats overexpressing } \\
\text { human CETP produce atherosclerosis }\end{array}$ & Highly resistant to atherogenesis, high HDL, and no CETP \\
\hline Hamsters & $\begin{array}{l}\text { Have plasma CETP, could develop hypercholesterolemia } \\
\text { and early atherosclerosis of fatty streaks and complex } \\
\text { plaques after various duration of diet induction, and } \\
\text { easy to handle }\end{array}$ & The inconsistent and unrepeatable results of aortic lesions \\
\hline Guinea pigs & $\begin{array}{l}\text { The majority of circulating cholesterol is LDL, possess } \\
\text { CETP, lipoprotein lipase, and LCAT, resignficant } \\
\text { atherogenic inflammation with increased aortic cytokines }\end{array}$ & $\begin{array}{l}\text { No advanced atherosclerotic lesions, antibodies involved in } \\
\text { atherogenic inflammation are rarely available, and not a good } \\
\text { surgical model }\end{array}$ \\
\hline Avian & $\begin{array}{l}\text { Atherosclerosis-susceptible strains, location and } \\
\text { progress of lesions similar to those in humans, low } \\
\text { cost and easy handling, sufficient size, good response } \\
\text { to dietary cholesterol, short generation time, and } \\
\text { relatively long life span }\end{array}$ & $\begin{array}{l}\text { Non-mammalian, lack of apoE, } \mathrm{B}_{48} \text {, and chylomicron forma- } \\
\text { tion, viral infection seen associated with atherosclerosis, and } \\
\text { considerable changes in lipoprotein metabolism during egg- } \\
\text { laying }\end{array}$ \\
\hline Dogs & $\begin{array}{l}\text { Some physiological/anatomical similarities to humans, } \\
\text { well-characterized lipoprotein profile, hematologic and } \\
\text { metabolic similarities to humans, extensive literature } \\
\text { on blood pressure-altering drugs and drug interactions, } \\
\text { and prosthetic devices }\end{array}$ & $\begin{array}{l}\text { Atherosclerosis-resistant species, high HDL, expensive, no } \\
\text { advanced atherosclerotic lesions, poor response to dietary } \\
\text { cholesterol, ethical concerns, large amount of experimental } \\
\text { agents needed, and spontaneous bacteremias and viral } \\
\text { infections }\end{array}$ \\
\hline Swine & $\begin{array}{l}\text { Some physiological/anatomical similarities to humans, } \\
\text { spontaneous atherosclerosis particularly in abdominal } \\
\text { aorta, availability of miniature pigs, natural lipoprotein } \\
\text { mutant strains, advanced vulnerable carotid } \\
\text { atherosclerotic plaques, and surgical study of } \\
\text { carotid artery stent techniques }\end{array}$ & $\begin{array}{l}\text { High cholesterol diet }(4 \%-5 \% \mathrm{w} / \mathrm{w}) \text {, longer time diet induction, } \\
\text { very low baseline cholesterol level, difficulties in care, and high } \\
\text { maintenance cost }\end{array}$ \\
\hline $\begin{array}{l}\text { Non-human } \\
\text { primates }\end{array}$ & $\begin{array}{l}\text { The closest species to humans, some strains respond } \\
\text { well to dietary cholesterol, spontaneous early stage } \\
\text { atherosclerosis in some strains, familial LDL receptor } \\
\text { deficiency, and surgical angioplasty study }\end{array}$ & $\begin{array}{l}\text { Serious chronic kidney disease is the outcome of athero- } \\
\text { sclerosis research (resulting in high risk of premature death), } \\
\text { variations in site of lesions, limited availability, expensive and } \\
\text { difficult to house and handle, and ethical concerns }\end{array}$ \\
\hline
\end{tabular}

LDL, low-density lipoprotein; HDL, high-density lipoprotein; CETP, cholesteryl ester transfer protein; apo, apolipoprotein; LCAT, lecithin-cholesterol acyl transferase.

spontaneously develop atherosclerosis, and the plaques are widespread and reproducible, particularly those regulating monocyte adherence/chemotaxis and macrophage differentiation/foam cell development. While the sites of lesion are very different from human lesions (i.e., mainly in the aortic root with a foam cell-rich pattern instead of the aortic root and the smooth muscle cell-rich thoracic aorta, which may not have a single definable fibrous cap) and represent xanthomata rather than clinically important advanced lesions. In fact, these mice are models of atherogenesis, not advanced atherosclerosis, and they do not exhibit the single most important event in human atherosclerosis, i.e., plaque rupture leading to vessel occlusion. Various mouse models of plaque rupture have been created in apoE or low-attenuation lipoprotein-receptor KO mice, but whether they represent the same type of plaque rupture is still debated. The advantages of the mouse model include low cost, reproducibility, and the availability of a transgenic technique to dissect the relevant pathologic processes. However, the size of the vessels and hemodynamic factors are very different from those in humans, making it difficult to directly translate results to patients (Table 1). 
Rats

Like mice, rats do not have plasma CETP either, are generally considered to be resistant to atherogenesis, and $\sim 80 \%$ of the total plasma cholesterol is in HDL particles (Fig. 2) (Fernandez et al., 1999); moreover, rats are very efficient in converting cholesterol to bile acids. Notably, certain strains of SHR are particularly susceptible to developing diet-induced, lipid-containing lesions in their arteries (Okamoto et al., 1964). The lesions in rats are not very similar to those seen in humans; the lipid-containing lesions are generally considered to be residual lesions following an acute arteritis (Table 1). Rats are generally hypo-responsive to dietary cholesterol. Thus, hyperlipidemia and atherogenesis may only be induced in rats by high cholesterol/high fat diets containing cholic acid and thiouracil (Joris et al., 1983). Several strains of rats with heritable hyperlipidemia, and some of those associated with atherogenesis, have been described (St. John and Bell, 1991; Russell et al., 1993; Chinellato et al., 1994). Thus far, however, few transgenic rats (e.g., those overexpressing human CETP in a DS hypertensive strain) have been shown to produce atherosclerosis (Herrera et al., 1999).

Hamsters

Hamsters, unlike mice and rats but similar to humans, have plasma CETP, and approximately $49 \%$ and $48 \%$ of the total plasma cholesterol is in HDL and LDL particles, respectively (Fig. 2) (Fernandez et al., 1999). It has been reported that male Golden Syrian hamsters develop hypercholesterolemia and early atherosclerosis of fatty streaks in the ascending aorta over a period of 2 months (Nistor et al., 1987) on atherogenic diets.

Due to their ease of handling and being more like humans in their response to diet modification than most other rodents, the Syrian hamster has emerged as a viable animal model for atherosclerosis research. Four Golden-Syrian hamster strains have predominantly been used to study diet-induced atherosclerosis. In these strains, no lesions are found in the descending and abdominal aorta, but with continued exposure to a fatty diet, the lesions can progress into complex plaques resembling human lesions. After 1 month of a diet of cholesterol and saturated fat, Syrian hamsters develop subendothelial foam cells, which are precursors of fatty streaks. The atherogenic diet results in a $<200 \%$ increase in very low-density lipoprotein (VLDL)/LDL cholesterol, a $20 \%$ increase in LDL cholesterol, and a $45 \%$ decrease in HDL cholesterol concentrations compared to controls (Nistor et al., 1987).

Even with the limited data to date, the inbred F1B hamster has been more consistently reported to develop an atherogenic lipoprotein profile than any of the other three outbred strains (i.e., CR, Sasco (Kahlon et al., 1996; Kahlon et al., 1997), and Harlan hamsters (Lock et al., 2005; Tyburczy et al., 2009); for a review, see (Dillard et al., 2010)). However, due to the inconsistent and unrepeatable results of aortic lesions in response to dietary fat type in recent studies, hamsters are no longer a suitable model for studying dietinduced atherosclerosis (Dillard et al., 2010) (Table 1).

\section{Guinea pigs}

The most striking similarity between guinea pigs and humans is that the majority of their circulating cholesterol is transported in LDL particles (Fig. 2) (Fernandez et al., 1999). Additionally, guinea pigs resemble human by possessing CEPT, lipoprotein lipase, and LCAT (Grove and Pownall, 1991). It has been shown that high cholesterol diets induce aortic cholesterol accumulation in guinea pigs and that certain dietary components or drug treatment can reduce the concentrations of cholesterol in their aorta, even in the presence of very high dietary cholesterol (Fernandez and Volek, 2006). Further, significant atherogenic inflammation with an increase in aortic cytokines has been documented in guinea pigs. The mechanisms of certain drugs affecting triglyceride metabolism can also be explored (Aggarwal et al., 2005; Aggarwal et al., 2006). However, no advanced atherosclerotic lesions have been observed in guinea pigs (Lynch et al., 1996; Singh et al., 2009), and the literature considering guinea pigs as surrogates to surgical models is quite sparse. Additionally, antibodies for studying the pathways involved in atherogenic inflammation are lacking.

\section{Avian}

Birds are inexpensive to maintain and breed, and some species spontaneously develop atherosclerosis, which can be enhanced by high cholesterol diet. To date, three species have been used for atherosclerosis research: pigeons, Japanese quail, and chickens. The most striking similarities between avian and humans are the characteristics of advanced lesions, such as intimal thickness, necrosis, and infarction (Shih et al., 1983), making them a popular choice for atherosclerotic study (Table 1). However, birds have no apoE or apoB48 and do not form chylomicrons when absorbing fat (St Clair, 1998), which indicates differences in lipid and lipoprotein metabolism between avian and humans. Moreover, birds harbor a variety of viruses that have also been reported to induce atherosclerosis (Lehner et al., 1967; Fabricant et al., 1978; Hajjar et al., 1986; Pătraşcu, 1987).

\section{Pigeons}

Atherosclerosis was first demonstrated in pigeons in 1959 (Clarkson et al., 1959). The White Carneau (WC) strain develops spontaneous atherosclerosis (St Clair, 1983; Barakat and St Clair, 1985), and Show Racer (SR) pigeons 
are resistant to atherogenesis, even when fed a high cholesterol diet (Barakat and St Clair, 1985). The WC develops macrophage foam cells (Taylor and Lewis, 1986) and atheromas in the thoracic aorta, abdominal aorta, brachiocephalic, iliac, carotid, renal, and coronary arteries (Prichard et al., 1964).

\section{Quails}

A large amount of atherosclerosis-related data were generated in quails after Ojerio et al. (1972) demonstrated dietinduced atherosclerosis and myocardial infarction in this system (Ojerio et al., 1972). The susceptible Japanese quail strain is responsive to cholesterol feeding (Shih et al., 1983). Although the majority of circulating cholesterol in quails is transported in HDL particles (Fig. 2) (Hammad et al., 1998), diet-induced hypercholesterolemia is associated with a significant shift in LDL and VLDL in serum (Ojerio et al., 1972). Increased levels of plasma cholesterol correlate with an increased frequency and severity of atherosclerotic lesions (Oku et al., 1993).

These atherosclerotic lesions result in further complications, such as thickened intima, stenosis, necrosis, and infarction. Further, the nature of the lesions is similar to that in humans (Shih et al., 1983). Altogether, the reproducibility of advanced lesions, along with a well-defined genetic background, makes the atherosclerosis-susceptible Japanese quail attractive in dyslipidemia and atherosclerosis research (Ojerio et al., 1972; Shih et al., 1983; Oku et al., 1993).

\section{Chickens}

Atherosclerosis develops spontaneously in the aorta and coronary arteries of chickens and at an accelerated rate when fed a cholesterol-diet (Dauber, 1944; Dauber et al., 1949). Further, atherosclerotic lesions can be induced in both abdominal and thoracic aorta in chicks within 2 weeks by cholesterol feeding (Saltykow, 1908). However, the major limitation of this model in studying human atherosclerosis is that the lesions are not advanced. Thus, chickens better serve as a model for atherogenesis.

\section{Carnivores}

\section{Dogs}

The cardiovascular physiology and anatomy of dogs are similar to that of humans (Miller et al., 1956), and dogs also display hematologic and metabolic similarities to humans. Additionally, dogs have been extensively used in studies on blood pressure altering drugs and drug interactions (Keech et al., 1986), as well as prosthetic devices (Sauvage et al., 1974). All of these facts make dogs attractive animals for atherosclerosis research. Generally, dogs are resistant to diet-induced atherogenesis, and $\sim 75 \%$ of their total plasma cholesterol is found in HDL particles (Fig. 2) (Wasan et al., 1998), which may be due to the lack of plasma CETP. Spontaneous atherosclerosis is rare in dogs; even a high cholesterol diet does not result in the development of advanced atherosclerotic lesions (Mahley et al., 1974). However, induction of experimental atherosclerosis in dogs is possible with the use of a high fat/high cholesterol (up to $5 \%$ $w / w$ ) diet deficient in essential fatty acids (Mahley et al., 1974; Butkus et al., 1976). Hypercholesterolemia and atherosclerosis can also be induced in foxhounds by dietary means (Kent and Whitney, 1982), though a poor response to dietary cholesterol limits further study (Narayanaswamy et al., 2000). Regardless of these, some surgical studies have tested venous graft replacements in the dog (Chue et al., 2004). Additional disadvantages to using dogs as a model organism include the vast array of experimental agents required and certain ethical issues. Dogs also frequently exhibit spontaneous bacteremias and viral infections (Hancock et al., 1980; Nojiri et al., 1987), which limit their further use for graft responses.

\section{Cats}

Cats have not been widely used in studies of atherosclerosis because they are resistant to atherosclerosis. Only a few exceptions report spontaneous and diet-induced atherosclerosis in domestic cats (Wisselink et al., 1994; Ginzinger et al., 1997).

\section{Swine}

Swine are like humans in the fact that the majority of their circulating cholesterol is transported in LDL particles $160 \%$ in swine vs $63 \%$ in human; $38 \%$ is in HDL in swine vs $28 \%$ in humans) (Fig. 2), and their hemodynamic and metabolic values are similar to humans (Liedtke et al., 1975). The development, morphology, and function of the normal cardiovascular system in swine also closely resembles that of humans (McKenzie et al., 1996). For instance, the coronary vasculature of a pig heart is nearly identical to that of humans in anatomic distribution, reactivity, and collectoral flow (McKenzie et al., 1996). The electrophysiologic parameters of pigs also more closely resemble those of man than other models, except the non-human primate (Liedtke et al., 1975; Bowman and Hughes, 1984; Hughes, 1986). Moreover, cardiovascular surgical procedures using swine have been technically feasible for ventricular assist devices for patients suffering from acute myocardial infarction (Vyavahare et al., 1999; Schoen and Levy, 2009), vascular stents, and restenosis (David et al., 1998; David et al., 2009), which make swine a unique surgical model.

In addition, swine develop spontaneous atherosclerosis with increased age (Skold et al., 1966). Naturally defective 
pigs with Lpb5 and Lpu1 mutations develop hypercholesterolemia and atherosclerosis in the coronary, iliac, and femoral arteries on low fat cholesterol-free diets (Rapacz et al., 1986; Prescott et al., 1991). The miniature pig is one of the breeds developed and used for medical research, but an extremely high cholesterol level $(4 \% \mathrm{w} / \mathrm{w})$ is needed to induce advanced atherosclerotic lesions in coronary arteries of miniature pigs (Holvoet et al., 1998). Regardless of these, the atherosclerotic swine has been extensively characterized over the last 4 decades (Gerrity et al., 1979; Gerrity, 1984; Gerrity et al., 1985; Bell and Gerrity, 1992; El-Khatib et al., 2007).

Spontaneous rupture was considered an extremely rare or non-existent event in animal models of atherosclerosis. Gerrity et al. examined distal embolism in the swine model to confirm the presence of vulnerable carotid atherosclerotic plaques (Gerrity et al., 2001). This swine model of carotid atherosclerosis contains many morphologic features of vulnerable carotid atherosclerotic plaques (e.g., a necrotic core, a thin fibrous cap, and intraplaque hemorrhage), and these features are frequently observed in symptomatic carotid atherosclerotic plaques obtained at endarterectomy. Magnetic resonance (MR) imaging studies have established the association of these carotid plaque characteristics with ischemic events in initially asymptomatic patients. The finding of distal atheroembolism fulfills the functional definition of vulnerable plaque in this animal model. Without the intervening rete mirabile, these emboli would have traveled to the brain and caused infarcts (Gerrity et al., 2001). Clinical study of carotid artery stent techniques has also been applied in swine (Ishii et al., 2006). All of these reports have proven pigs to be an excellent model for studying the basic mechanisms, pathophysiology, and progression of atherosclerosis. However, their relatively high cost of maintenance and longer diet-induction time hinder the broader use of swine (Table 1).

\section{Non-human primates}

Non-human primates are attractive models for human diseases; it is plausible that data derived from these animals are more directly applicable to man. Spontaneous atherosclerosis is observed in monkeys (Taylor et al., 1954), and the development of atherosclerotic lesions and fatal myocardial infarction can be induced in rhesus monkeys fed a high cholesterol diet (Taylor et al., 1954; Andrus and Mann, 1956). To date, similar observations have been demonstrated by Mann et al. (1953), Taylor et al. (1959), Lindsay and Chaikoff (1966), Armstrong and Warner (1971) and Armstrong and Heistad (1990) to review and characterize dyslipidemia and atherosclerosis in non-human primates.

This abnormal lipid profile is associated with the development of extensive atherosclerotic lesions in the aorta and all its major branches, including the coronary and cerebral vessels. Further, these lesions are similar to those seen in humans. Recently familial LDL receptor deficiency with atherosclerosis has been reported in rhesus monkey (Scanu et al., 1988; Kusumi et al., 1993). Hyper- and hyporesponsiveness to a cholesterol diet has also been reported in monkey species (Clarkson et al., 1976). The location of atheromas varies among different strains of monkeys. The most interesting finding from Dr. Geary's research has been the tremendous involvement of remodeling to favorable responses to angioplasty using cynomolgus macaques (Geary et al., 1996). However, the complications of serious chronic kidney disease are the outcomes of atherosclerosis research in New World monkeys, which modulates both their lipoprotein metabolism and their atherosclerosis (Clarkson et al., 1976), and has limited the use of non-human primates in such research. Patients with chronic kidney disease develop accelerated atherosclerosis and are at high risk of premature death from cardiovascular disease (Go et al., 2004, 2006; Kovesdy et al., 2006). Aside from the high cost of experiments and difficulties in handling, ethical issues also hamper the usage of non-human primates for study (Table 1).

\section{INSIGHT AND PERSPECTIVE}

We are faced with the challenge of the growing incidence/ prevalence of cardiovascular diseases in humans. Over the past century, a variety of experimental procedures have been used to investigate the pathophysiology of one of these diseases, atherosclerosis. As a result, laboratory animals have been extensively used in atherosclerosis research. Looking ahead, transgenic animals are expected to shed light on the molecular pathogenesis of atherosclerosis by elucidating the cause-and-effect relationships in lesion initiation and progression. Regardless, all of the accomplishments listed above have substantially enhanced our understanding of this disease.

"Cholesterol theory" was one of the first hypotheses and still remains at the center of almost all research activity in this field. Cholesterol-lowering agents, particularly the statins (Moghadasian, 1999), have been extremely promising. However, studies indicate that reduction of plasma cholesterol levels should not be the only tactic in the treatment or prevention of atherosclerotic vascular disease. Our understanding of the process of atherosclerosis lesions is still incomplete. Oxidative stress (Witztum and Steinberg, 1991), inflammation (Ross, 1999), hyperhomocyst(e)inemia (Moghadasian et al., 1997), infection (Chlamydia pneumoniae) (Fong, 2000), and other emerging risk factors (e.g., diabetic atherosclerosis (Grundy et al., 2002)) should be carefully considered in the management of this potentially fatal disease. The current established models and new emerging models will provide useful approaches for studying the mechanism(s) of disease progression, as well as serve as valuable tools for evaluating therapeutic options. 


\section{ACKNOWLEDGEMENTS}

This work was supported by grants from the Ministry of Science and Technology of China (MOST) (Grant No. 2011CB944103), and the Natural Science Foundation of Beijing Council (Grant No. 5111002) to $\mathrm{X}$. $\mathrm{Li}$, and the grant from the MOST (Grant No. 2011CBA01000) to N. Li.

\section{REFERENCES}

Abela, G.S., Picon, P.D., Friedl, S.E., Gebara, O.C., Miyamoto, A., Federman, M., Tofler, G.H., and Muller, J.E. (1995). Triggering of plaque disruption and arterial thrombosis in an atherosclerotic rabbit model. Circulation 91, 776-784.

Adams, C.W.M., Miller, N.E., Morgan, R.S., and Rao, S.N. (1982). Lipoprotein levels and tissue lipids in fatty-fibrous atherosclerosis induced in rabbits by two years' cholesterol feeding at a low level. Atherosclerosis 44, 1-8.

Aggarwal, D., Fernandez, M.L., and Soliman, G.A. (2006). Rapamycin, an mTOR inhibitor, disrupts triglyceride metabolism in guinea pigs. Metabolism 55, 794-802.

Aggarwal, D., West, K.L., Zern, T.L., Shrestha, S., Vergara-Jimenez, M., and Fernandez, M.L. (2005). JTT-130, a microsomal triglyceride transfer protein (MTP) inhibitor lowers plasma triglycerides and LDL cholesterol concentrations without increasing hepatic triglycerides in guinea pigs. BMC Cardiovasc Disord 5, 30.

Aikawa, M., Rabkin, E., Voglic, S.J., Shing, H., Nagai, R., Schoen, F. J., and Libby, P. (1998). Lipid lowering promotes accumulation of mature smooth muscle cells expressing smooth muscle myosin heavy chain isoforms in rabbit atheroma. Circ Res 83, 1015-1026.

Aliev, G., and Burnstock, G. (1998). Watanabe rabbits with heritable hypercholesterolaemia: a model of atherosclerosis. Histol Histopathol 13, 797-817.

Anitschkow, N., and Chalatow, S. (1913). Uber experimentelle Cholesterinsteatose und ihre Bedeutung fur die Entstehung einiger pathologischer Prozesse. Centrbl Allg Pathol Pathol Anat 24, 1-9.

Armstrong, M.L., and Heistad, D.D. (1990). Animal models of atherosclerosis. Atherosclerosis 85, 15-23.

Armstrong, M.L., and Warner, E.D. (1971). Morphology and distribution of diet-induced atherosclerosis in rhesus monkeys. Arch Pathol 92, 395-401.

Association, A.H. (2010). Heart Disease and Stroke Statistics-2009 Update (All Charts) [Accessed August 17, 2009]. Available at: http://wwwamericanheartorg/presenterjhtml? identifier = 3018163 .

Barakat, H.A., and St Clair, R.W. (1985). Characterization of plasma lipoproteins of grain- and cholesterol-fed White Carneau and Show Racer pigeons. J Lipid Res 26, 1252-1268.

Bell, F.P., and Gerrity, R.G. (1992). Evidence for an altered lipid metabolic state in circulating blood monocytes under conditions of hyperlipemia in swine and its implications in arterial lipid metabolism. Arterioscler Thromb 12, 155-162.

Bocan, T.M.A., Mueller, S.B., Mazur, M.J., Uhlendorf, P.D., Brown, E. Q., and Kieft, K.A. (1993). The relationship between the degree of dietary-induced hypercholesterolemia in the rabbit and atherosclerotic lesion formation. Atherosclerosis 102, 9-22.

Bowman, T.A., and Hughes, H.C. (1984). Swine as an in vivo model for electrophysiologic evaluation of cardiac pacing parameters. Pacing Clin Electrophysiol 7, 187-194.
Breslow, J.L. (1996). Mouse models of atherosclerosis. Science 272, 685-688.

Brousseau, M.E., and Hoeg, J.M. (1999). Transgenic rabbits as models for atherosclerosis research. J Lipid Res 40, 365-375.

Butkus, A., Ehrhart, L.A., and McCullagh, K.G. (1976). Plasma and aortic lipids in experimental canine atherosclerosis. Exp Mol Pathol 25, 152-162.

Chinellato, A., Ragazzi, E., Petrelli, L., Paro, M., Mironov, A., and Aliev, G. (1994). Effect of cholesterol-supplemented diet in heritable hyperlipidemic Yoshida rats: functional and morphological characterization of thoracic aorta. Atherosclerosis 106, 51-63.

Chue, W.L., Campbell, G.R., Caplice, N., Muhammed, A., Berry, C.L., Thomas, A.C., Bennett, M.B., and Campbell, J.H. (2004). Dog peritoneal and pleural cavities as bioreactors to grow autologous vascular grafts. J Vasc Surg 39, 859-867.

Clarkson, T.B., Lehner, N.D., Bullock, B.C., Lofland, H.B., and Wagner, W.D. (1976). Atherosclerosis in new world monkeys. Primates Med 9, 90-144.

Clarkson, T.B., Prichard, R.W., Netsky, M.G., and Lofland, H.B. (1959). Atherosclerosis in pigeons; its spontaneous occurrence and resemblance to human atherosclerosis. AMA Arch Pathol 68, 143-147.

Cornhill, J.F., and Roach, M.R. (1974). Quantitative method for the evaluation of atherosclerotic lesions. Atherosclerosis 20, 131-136.

Cornhill, J.F., and Roach, M.R. (1976). A quantitative study of the localization of atherosclerotic lesions in the rabbit aorta. Atherosclerosis 23, 489-501.

Dauber, D., Horlick, L., and Katz, L.N. (1949). The role of desiccated thyroid and potassium iodide in the cholesterol-induced atherosclerosis of the chicken. Am Heart J 38, 25-33.

Dauber, D.V. (1944). Spontaneous atherosclerosis in chickens. AMA Arch Pathol 38, 46-51.

David, T.E., Armstrong, S., Maganti, M., Butany, J., Feindel, C.M., and Bos, J. (2009). Postimplantation morphologic changes of glutaraldehyde-fixed porcine aortic roots and risk of aneurysm and rupture. J Thorac Cardiovasc Surg 137, 94-100.

David, T.E., Puschmann, R., Ivanov, J., Bos, J., Armstrong, S., Feindel, C.M., and Scully, H.E. (1998). Aortic valve replacement with stentless and stented porcine valves: a case-match study. J Thorac Cardiovasc Surg 116, 236-241.

Davies, M.K., and Hollman, A. (1998). Atherosclerosis and myocardial infarction. Heart 79, 218.

Dillard, A., Matthan, N.R., and Lichtenstein, A.H. (2010). Use of hamster as a model to study diet-induced atherosclerosis. Nutr Metab (Lond) 7, 89.

Duverger, N., Kruth, H., Emmanuel, F., Caillaud, J.M., Viglietta, C., Castro, G., Tailleux, A., Fievet, C., Fruchart, J.C., Houdebine, L.M., et al. (1996). Inhibition of atherosclerosis development in cholesterol-fed human apolipoprotein A-I-transgenic rabbits. Circulation 94, 713-717.

El-Khatib, F.H., Jiang, J., Gerrity, R.G., and Damiano, E.R. (2007). Pharmacodynamics and stability of subcutaneously infused glucagon in a type 1 diabetic Swine model in vivo. Diabetes Technol Ther 9, 135-144.

Fabricant, C.G., Fabricant, J., Litrenta, M.M., and Minick, C.R. (1978). Virus-induced atherosclerosis. J Exp Med 148, 335-340.

Fan, J., McCormick, S.P.A., Krauss, R.M., Taylor, S., Quan, R., Taylor, 
J.M., and Young, S.G. (1995). Overexpression of human apolipoprotein B-100 in transgenic rabbits results in increased levels of LDL and decreased levels of HDL. Arterioscler Thromb Vasc Biol 15, 1889-1899.

Fan, J., Shimoyamada, H., Sun, H., Marcovina, S., Honda, K., and Watanabe, T. (2001a). Transgenic rabbits expressing human apolipoprotein(a) develop more extensive atherosclerotic lesions in response to a cholesterol-rich diet. Arterioscler Thromb Vasc Biol 21, 88-94.

Fan, J., Unoki, H., Kojima, N., Sun, H., Shimoyamada, H., Deng, H., Okazaki, M., Shikama, H., Yamada, N., and Watanabe, T. (2001b). Overexpression of lipoprotein lipase in transgenic rabbits inhibits diet-induced hypercholesterolemia and atherosclerosis. J Biol Chem 276, 40071-40079.

Fan, J., Wang, J., Bensadoun, A., Lauer, S.J., Dang, Q., Mahley, R. W., and Taylor, J.M. (1994). Overexpression of hepatic lipase in transgenic rabbits leads to a marked reduction of plasma high density lipoproteins and intermediate density lipoproteins. Proc Natl Acad Sci U S A 91, 8724-8728.

Fernandez, M.L., and Volek, J.S. (2006). Guinea pigs: a suitable animal model to study lipoprotein metabolism, atherosclerosis and inflammation. Nutr Metab (Lond) 3, 17.

Fernandez, M.L., Wilson, T.A., Conde, K., Vergara-Jimenez, M., and Nicolosi, R.J. (1999). Hamsters and guinea pigs differ in their plasma lipoprotein cholesterol distribution when fed diets varying in animal protein, soluble fiber, or cholesterol content. J Nutr 129, 1323-1332.

Finking, G., and Hanke, H. (1997). Nikolaj Nikolajewitsch Anitschkow (1885-1964) established the cholesterol-fed rabbit as a model for atherosclerosis research. Atherosclerosis 135, 1-7.

Fong, I.W. (2000). Emerging relations between infectious diseases and coronary artery disease and atherosclerosis. CMAJ 163, 49-56.

Geary, R.L., Williams, J.K., Golden, D., Brown, D.G., Benjamin, M.E., and Adams, M.R. (1996). Time course of cellular proliferation, intimal hyperplasia, and remodeling following angioplasty in monkeys with established atherosclerosis. A nonhuman primate model of restenosis. Arterioscler Thromb Vasc Biol 16, 34-43.

Gerrity, R.G. (1984). Atherogenesis in the swine Evans blue model. Vasa 13, 292-297.

Gerrity, R.G., Goss, J.A., and Soby, L. (1985). Control of monocyte recruitment by chemotactic factor(s) in lesion-prone areas of swine aorta. Arteriosclerosis 5, 55-66.

Gerrity, R.G., Naito, H.K., Richardson, M., and Schwartz, C.J. (1979). Dietary induced atherogenesis in swine. Morphology of the intima in prelesion stages. Am J Pathol 95, 775-792.

Gerrity, R.G., Natarajan, R., Nadler, J.L., and Kimsey, T. (2001). Diabetes-induced accelerated atherosclerosis in swine. Diabetes 50, 1654-1665.

Ginzinger, D.G., Wilson, J.E., Redenbach, D., Lewis, M.E., Clee, S. M., Excoffon, K.J., Rogers, Q.R., Hayden, M.R., and McManus, B. M. (1997). Diet-induced atherosclerosis in the domestic cat. Lab Invest 77, 409-419.

Glass, C.K., and Witztum, J.L. (2001). Atherosclerosis. the road ahead. Cell 104, 503-516.

Go, A.S., Chertow, G.M., Fan, D., McCulloch, C.E., and Hsu, C.Y. (2004). Chronic kidney disease and the risks of death, cardiovascular events, and hospitalization. N Engl J Med 351, 1296-1305.
Go, A.S., Yang, J., Ackerson, L.M., Lepper, K., Robbins, S., Massie, B.M., and Shlipak, M.G. (2006). Hemoglobin level, chronic kidney disease, and the risks of death and hospitalization in adults with chronic heart failure: the Anemia in Chronic Heart Failure: Outcomes and Resource Utilization (ANCHOR) Study. Circulation 113, 2713-2723.

Grove, D., and Pownall, H.J. (1991). Comparative specificity of plasma lecithin:cholesterol acyltransferase from ten animal species. Lipids 26, 416-420.

Grundy, S.M., Howard, B., Smith, S. Jr, Eckel, R., Redberg, R., and Bonow, R.O. (2002). Prevention Conference VI: Diabetes and Cardiovascular Disease: executive summary: conference proceeding for healthcare professionals from a special writing group of the American Heart Association. Circulation 105, 2231-2239.

Hajjar, D.P., Fabricant, C.G., Minick, C.R., and Fabricant, J. (1986). Virus-induced atherosclerosis. Herpesvirus infection alters aortic cholesterol metabolism and accumulation. Am J Pathol 122, 62-70.

Hammad, S.M., Siegel, H.S., and Marks, H.L. (1998). Total cholesterol, total triglycerides, and cholesterol distribution among lipoproteins as predictors of atherosclerosis in selected lines of Japanese quail. Comp Biochem Physiol A Mol Integr Physiol 119, 485-492.

Hancock, J.B., Forshaw, P.L., and Kaye, M.P. (1980). Gore-Tex (polytetrafluoroethylene) in canine coronary artery bypass. J Thorac Cardiovasc Surg 80, 94-101.

Hansson, G.K. (2005). Inflammation, atherosclerosis, and coronary artery disease. N Engl J Med 352, 1685-1695.

Hansson, G.K. (2009). Atherosclerosis-an immune disease: The Anitschkov Lecture 2007. Atherosclerosis 202, 2-10.

Herrera, V.L.M., Makrides, S.C., Xie, H.X., Adari, H., Krauss, R.M., Ryan, U.S., and Ruiz-Opazo, N. (1999). Spontaneous combined hyperlipidemia, coronary heart disease and decreased survival in Dahl salt-sensitive hypertensive rats transgenic for human cholesteryl ester transfer protein. Nat Med 5, 1383-1389.

Hoeg, J.M., Santamarina-Fojo, S., Bérard, A.M., Cornhill, J.F., Herderick, E.E., Feldman, S.H., Haudenschild, C.C., Vaisman, B. L., Hoyt, R.F. Jr, Demosky, S.J. Jr, et al. (1996). Overexpression of lecithin:cholesterol acyltransferase in transgenic rabbits prevents diet-induced atherosclerosis. Proc Natl Acad Sci U S A 93, 11448-11453.

Hoeg, J.M., Vaisman, B.L., Demosky, S.J. Jr, Santamarina-Fojo, S., Brewer, H.B. Jr, Remaley, A.T., Hoyt, R.F., and Feldman, S. (1993). Development of transgenic Watanabe Heritable Hyperlipidemic rabbits expressing human apolipoprotein A-I. Circulation 88, $1-2$.

Holvoet, P., Theilmeier, G., Shivalkar, B., Flameng, W., and Collen, D. (1998). LDL hypercholesterolemia is associated with accumulation of oxidized LDL, atherosclerotic plaque growth, and compensatory vessel enlargement in coronary arteries of miniature pigs. Arterioscler Thromb Vasc Biol 18, 415-422.

Hughes, H.C. (1986). Swine in cardiovascular research. Lab Anim Sci 36, 348-350.

Hunt, C.E., and Duncan, L.A. (1985). Hyperlipoproteinaemia and atherosclerosis in rabbits fed low-level cholesterol and lecithin. $\mathrm{Br} \mathrm{J}$ Exp Pathol 66, 35-46.

Ignatowski, A.C. (1908). Influence of animal food on the organism of rabbits. Izv Imp Voyenno-Med Akad Peter 16, 154-173. 
Ishii, A., Viñuela, F., Murayama, Y., Yuki, I., Nien, Y.L., Yeh, D.T., and Vinters, H.V. (2006). Swine model of carotid artery atherosclerosis: experimental induction by surgical partial ligation and dietary hypercholesterolemia. AJNR Am J Neuroradiol 27, 1893-1899.

Johnstone, M.T., Botnar, R.M., Perez, A.S., Stewart, R., Quist, W.C., Hamilton, J.A., and Manning, W.J. (2001). In vivo magnetic resonance imaging of experimental thrombosis in a rabbit model. Arterioscler Thromb Vasc Biol 21, 1556-1560.

Joris, I., Zand, T., Nunnari, J.J., Krolikowski, F.J., and Majno, G. (1983). Studies on the pathogenesis of atherosclerosis. I. Adhesion and emigration of mononuclear cells in the aorta of hypercholesterolemic rats. Am J Pathol 113, 341-358.

Kahlon, T., Chow, F., Irving, D., and Sayre, R. (1996). Cholesterol response and foam cell formation in hamsters fed two levels of saturated fat and various levels of cholesterol. Nutr Res 16, 1353-1368.

Kahlon, T.S., Chow, F.I., Irving, D.W., and Sayre, R.N. (1997). Cholesterol response and fatty streak formation in hamsters fed two levels of saturated fat and various levels of cholesterol. Nutr Res 17, 1693-1707.

Keech, A.C., Harper, R.W., Harrison, P.M., Pitt, A., and McLean, A.J. (1986). Pharmacokinetic interaction between oral metoprolol and verapamil for angina pectoris. Am J Cardiol 58, 551-552.

Kent, W.C., and Whitney, J.E. (1982). Cholesterol kinetics in control and hypercholesterolemic foxhounds. Artery 11, 15-32.

Kita, T., Nagano, Y., Yokode, M., Ishii, K., Kume, N., Ooshima, A., Yoshida, H., and Kawai, C. (1987). Probucol prevents the progression of atherosclerosis in Watanabe heritable hyperlipidemic rabbit, an animal model for familial hypercholesterolemia. Proc Natl Acad Sci U S A 84, 5928-5931.

Knopp, R.H. (1999). Drug treatment of lipid disorders. N Engl J Med 341, 498-511.

Knopp, R.H., and Paramsothy, P. (2006). Treatment of hypercholesterolemia in patients with metabolic syndrome: how do different statins compare? Nat Clin Pract Endocrinol Metab 2, 136-137.

Kolodgie, F.D., Katocs, A.S. Jr, Largis, E.E., Wrenn, S.M., Cornhill, J. F., Herderick, E.E., Lee, S.J., and Virmani, R. (1996). Hypercholesterolemia in the rabbit induced by feeding graded amounts of low-level cholesterol. Methodological considerations regarding individual variability in response to dietary cholesterol and development of lesion type. Arterioscler Thromb Vasc Biol 16, 1454-1464.

Kovesdy, C.P., Trivedi, B.K., and Anderson, J.E. (2006). Association of kidney function with mortality in patients with chronic kidney disease not yet on dialysis: a historical prospective cohort study. Adv Chronic Kidney Dis 13, 183-188.

Kritchevsky, D. (1995). Dietary protein, cholesterol and atherosclerosis: a review of the early history. J Nutr $125,589 S-593 S$.

Kritchevsky, D., Tepper, S.A., Williams, D.E., and Story, J.A. (1977). Experimental atherosclerosis in rabbits fed cholesterol-free diets. Part 7. Interaction of animal or vegetable protein with fiber. Atherosclerosis 26, 397-403.

Kusumi, Y., Scanu, A.M., McGill, H.C., and Wissler, R.W. (1993). Atherosclerosis in a rhesus monkey with genetic hypercholesterolemia and elevated plasma Lp(a). Atherosclerosis 99, 165-174.

Lehner, N.D., Bullock, B.C., and Clarkson, T.B. (1967). Intranuclear inclusion disease of pigeons. J Am Vet Med Assoc 151, 939-941.
Libby, P., and Aikawa, M. (2002). Stabilization of atherosclerotic plaques: new mechanisms and clinical targets. Nat Med 8, 1257-1262.

Liedtke, A.J., Hughes, H.C., and Neely, J.R. (1975). An experimental model for studying myocardial ischemia. Correlation of hemodynamic performance and metabolism in the working swine heart. J Thorac Cardiovasc Surg 69, 203-211.

Lindsay, S., and Chaikoff, I.L. (1966). Naturally occurring arteriosclerosis in nonhuman primates. J Atheroscler Res 6, 36-61.

Lock, A.L., Horne, C.A.M., Bauman, D.E., and Salter, A.M. (2005). Butter naturally enriched in conjugated linoleic acid and vaccenic acid alters tissue fatty acids and improves the plasma lipoprotein profile in cholesterol-fed hamsters. J Nutr 135, 1934-1939.

Lynch, S.M., Gaziano, J.M., and Frei, B. (1996). Ascorbic acid and atherosclerotic cardiovascular disease. Subcell Biochem 25, 331-367.

Mahley, R.W., Weisgraber, K.H., and Innerarity, T. (1974). Canine lipoproteins and atherosclerosis. II. Characterization of the plasma lipoproteins associated with atherogenic and nonatherogenic hyperlipidemia. Circ Res 35, 722-733.

Andrus, S.B., and Mann, G.V. (1956). Xanthomatosis and atherosclerosis produced by diet in an adult rhesus monkey. J Lab Clin Med 48, 533-550.

Mann, G.V., Andrus, S.B., McNALLY, A., and Stare, F.J. (1953). Experimental atherosclerosis in Cebus monkeys. J Exp Med 98, 195-218.

Marotti, K.R., Castle, C.K., Boyle, T.P., Lin, A.H., Murray, R.W., and Melchior, G.W. (1993). Severe atherosclerosis in transgenic mice expressing simian cholesteryl ester transfer protein. Nature 364 , 73-75.

McKenzie, J.E., Scandling, D.M., Ahle, N.W., Bryant, H.J., Kyle, R.R., and Abbrecht, P.H. (1996). Effects of soman (pinacolyl methylphosphonofluoridate) on coronary blood flow and cardiac function in swine. Fundam Appl Toxicol 29, 140-146.

Mezdour, H., Jones, R., Dengremont, C., Castro, G., and Maeda, N. (1997). Hepatic lipase deficiency increases plasma cholesterol but reduces susceptibility to atherosclerosis in apolipoprotein Edeficient mice. J Biol Chem 272, 13570-13575.

Miller, F.A., Perry, J.F. Jr, Thal, A., and Wangensteen, O.H. (1956). Direct suture anastomosis of the coronary arteries in the dog. Surgery 40, 1023-1029.

Moghadasian, M.H. (1999). Clinical pharmacology of 3-hydroxy-3methylglutaryl coenzyme A reductase inhibitors. Life Sci 65 , 1329-1337.

Moghadasian, M.H., McManus, B.M., and Frohlich, J.J. (1997). Homocyst(e)ine and coronary artery disease. Clinical evidence and genetic and metabolic background. Arch Intern Med 157, 2299-2308.

Mohrschladt, M.F., Westendorp, R.G.J., Gevers Leuven, J.A., and Smelt, A.H.M. (2004). Cardiovascular disease and mortality in statin-treated patients with familial hypercholesterolemia. Atherosclerosis $172,329-335$.

Narayanaswamy, M., Wright, K.C., and Kandarpa, K. (2000). Animal models for atherosclerosis, restenosis, and endovascular graft research. J Vasc Interv Radiol 11, 5-17.

Nishina, P.M., Verstuyft, J., and Paigen, B. (1990). Synthetic low and high fat diets for the study of atherosclerosis in the mouse. J Lipid Res 31, 859-869. 
Nistor, A., Bulla, A., Filip, D.A., and Radu, A. (1987). The hyperlipidemic hamster as a model of experimental atherosclerosis. Atherosclerosis 68, 159-173.

Nojiri, C., Noishiki, Y., and Koyanagi, H. (1987). Aorta-coronary bypass grafting with heparinized vascular grafts in dogs. A preliminary study. J Thorac Cardiovasc Surg 93, 867-877.

Ojerio, A.D., Pucak, G.J., Clarkson, T.B., and Bullock, B.C. (1972). Diet-induced atherosclerosis and myocardial infarction in Japanese quail. Lab Anim Sci 22, 33-39.

Okamoto, K., Aoki, K., Nosaka, S., and Fukushima, M. (1964). Cardiovascular Diseases in the Spontaneously Hypertensive Rat. Jpn Circ J 28, 943-952.

Oku, H., Ishikawa, M., Nagata, J., Toda, T., and Chinen, I. (1993). Lipoprotein and apoprotein profile of Japanese quail. Biochimica et Biophysica Acta - Lipids and Lipid Metabolism 1167, 22-28.

Organization, W.H. (2011). Cardiovascular Diseases Fact Sheet. [Accessed August 17, 2009]. Available at: http://wwwwhoint/ mediacentre/factsheets/fs317/en/printhtml.

Paigen, B., Morrow, A., Brandon, C., Mitchell, D., and Holmes, P. (1985). Variation in susceptibility to atherosclerosis among inbred strains of mice. Atherosclerosis 57, 65-73.

Pătraşcu, I.V. (1987). Marek's disease. XVII. Studies on virus induced-atherosclerosis. Virologie 38, 245-250.

Plump, A.S., Smith, J.D., Hayek, T., Aalto-Setälä, K., Walsh, A., Verstuyft, J.G., Rubin, E.M., and Breslow, J.L. (1992). Severe hypercholesterolemia and atherosclerosis in apolipoprotein Edeficient mice created by homologous recombination in ES cells. Cell 71, 343-353.

Prescott, M.F., McBride, C.H., Hasler-Rapacz, J., Von Linden, J., and Rapacz, J. (1991). Development of complex atherosclerotic lesions in pigs with inherited hyper-LDL cholesterolemia bearing mutant alleles for apolipoprotein B. Am J Pathol 139, 139-147.

Prichard, R.W., Clarkson, T.B., Goodman, H.O., and Lofland, H.B. (1964). Aortic Atherosclerosis in Pigeons and Its Complications. Arch Pathol 77, 244-257.

Purcell-Huynh, D.A., Farese, R.V. Jr, Johnson, D.F., Flynn, L.M., Pierotti, V., Newland, D.L., Linton, M.F., Sanan, D.A., and Young, S.G. (1995). Transgenic mice expressing high levels of human apolipoprotein B develop severe atherosclerotic lesions in response to a high-fat diet. J Clin Invest 95, 2246-2257.

Ramaswamy, M., Wallace, T.L., Cossum, P.A., and Wasan, K.M. (1999). Species differences in the proportion of plasma lipoprotein lipid carried by high-density lipoproteins influence the distribution of free and liposomal nystatin in human, dog, and rat plasma. Antimicrob Agents Chemother 43, 1424-1428.

Rapacz, J., Hasler-Rapacz, J., Taylor, K.M., Checovich, W.J., and Attie, A.D. (1986). Lipoprotein mutations in pigs are associated with elevated plasma cholesterol and atherosclerosis. Science 234, 1573-1577.

Rogers, K.A., and Karnovsky, M.J. (1988). A rapid method for the detection of early stages of atherosclerotic lesion formation. Am J Pathol 133, 451-455.

Ross, R. (1993). The pathogenesis of atherosclerosis: a perspective for the 1990s. Nature 362, 801-809.

Ross, R. (1999). Atherosclerosis-an inflammatory disease. N Engl J Med 340, 115-126.

Russell, J.C., Koeslag, D.G., Dolphin, P.J., and Amy, R.M. (1993). Beneficial effects of acarbose in the atherosclerosis-prone JCR:
LA-corpulent rat. Metabolism 42, 218-223.

Saltykow, S. (1908). Atherosklerose bei kaninchen nach weiderhotten staphylokokkeningjiktionen. Beitr Z Pathol Anat U Z Allg Pathol, Jena, 147-171.

Sauvage, L.R., Berger, K.E., Wood, S.J., Yates, S.G. 2nd, Smith, J.C., and Mansfield, P.B. (1974). Interspecies healing of porous arterial prostheses: observations, 1960 to 1974. Arch Surg 109, 698-705.

Scanu, A.M., Khalil, A., Neven, L., Tidore, M., Dawson, G., Pfaffinger, D., Jackson, E., Carey, K.D., McGill, H.C., and Fless, G.M. (1988). Genetically determined hypercholesterolemia in a rhesus monkey family due to a deficiency of the LDL receptor. J Lipid Res 29, 1671-1681.

Schoen, F.J., and Levy, R.J. (2009). SnapShot: calcification of bioprosthetic heart valves. Biomaterials 30, 4445-4446.

Shen, J., Herderick, E., Cornhill, J.F., Zsigmond, E., Kim, H.S., Kühn, H., Guevara, N.V., and Chan, L. (1996). Macrophage-mediated 15lipoxygenase expression protects against atherosclerosis development. J Clin Invest 98, 2201-2208.

Shih, J.C.H., Pullman, E.P., and Kao, K.J. (1983). Genetic selection, general characterization, and histology of atherosclerosissusceptible and -resistant Japanese quail. Atherosclerosis 49, 41-53.

Singh, V., Tiwari, R.L., Dikshit, M., and Barthwal, M.K. (2009). Models to study atherosclerosis: a mechanistic insight. Curr Vasc Pharmacol 7, 75-109.

Skold, B.H., Getty, R., and Ramsey, F.K. (1966). Spontaneous atherosclerosis in the arterial system of aging swine. Am J Vet Res 27, 257-273.

Spagnoli, L.G., Orlandi, A., Mauriello, A., Santeusanio, G., de Angelis, C., Lucreziotti, R., and Ramacci, M.T. (1991). Aging and atherosclerosis in the rabbit. 1. Distribution, prevalence and morphology of atherosclerotic lesions. Atherosclerosis 89, 11-24.

St Clair, R.W. (1983). Metabolic changes in the arterial wall associated with atherosclerosis in the pigeon. Fed Proc 42, 2480-2485.

St Clair, R.W. (1998). The contribution of avian models to our understanding of atherosclerosis and their promise for the future. Lab Anim Sci 48, 565-568.

St John, L.C., and Bell, F.P. (1991). Arterial lipid biochemistry in the spontaneously hyperlipidemic Zucker rat and its similarity to early atherogenesis. Atherosclerosis 86, 139-144.

Taylor, C.B., Cox, G.E., Counts, M., and Yogi, N. (1959). Fatal myocardial infarction in rhesus monkey with diet-induced hypercholesterolemia. Am J Pathol 35, 674.

Taylor, C.B., Cox, G.F., Hall-Taylor, B.J., and Nelson, L.G. (1954). Atherosclerosis in areas of vascular injury in monkeys with mild hypercholesterolemia. Circulation 10, 613.

Taylor, J.M., and Fan, J. (1997). Transgenic rabbit models for the study of atherosclerosis. Frontiers in Bioscience: a Journal and Virtual Library 2, 298-308.

Taylor, R.G., and Lewis, J.C. (1986). Endothelial cell proliferation and monocyte adhesion to atherosclerotic lesions of white carneau pigeons. Am J Pathol 125, 152-160.

Tyburczy, C., Major, C., Lock, A.L., Destaillats, F., Lawrence, P., Brenna, J.T., Salter, A.M., and Bauman, D.E. (2009). Individual trans octadecenoic acids and partially hydrogenated vegetable oil differentially affect hepatic lipid and lipoprotein metabolism in 
golden Syrian hamsters. J Nutr 139, 257-263.

Véniant, M.M., Zlot, C.H., Walzem, R.L., Pierotti, V., Driscoll, R., Dichek, D., Herz, J., and Young, S.G. (1998). Lipoprotein clearance mechanisms in LDL receptor-deficient "Apo-B48-only" and "Apo-B100-only" mice. J Clin Invest 102, 1559-1568.

Vyavahare, N., Ogle, M., Schoen, F.J., Zand, R., Gloeckner, D.C., Sacks, M., and Levy, R.J. (1999). Mechanisms of bioprosthetic heart valve failure: fatigue causes collagen denaturation and glycosaminoglycan loss. J Biomed Mater Res 46, 44-50.

Wasan, K.M., Ramaswamy, M., Ng, S.P., Wong, W., Parrott, S.C., Ojwang, J.O., Wallace, T., and Cossum, P.A. (1998). Differences in the lipoprotein distribution of free and liposome-associated alltrans-retinoic acid in human, dog, and rat plasma are due to variations in lipoprotein lipid and protein content. Antimicrob Agents Chemother 42, 1646-1653.

Watanabe, Y. (1980). Serial inbreeding of rabbits with hereditary hyperlipidemia (WHHL-rabbit). Atherosclerosis 36, 261-268.

West, C.E., Deuring, K., Schutte, J.B., and Terpstra, A.H.M. (1982). The effect of age on the development of hypercholesterolemia in rabbits fed semipurified diets containing casein. J Nutr 112, 1287-1295.

Wisselink, M.A., Koeman, J.P., Wensing, T., de Bruijne, J., and Willemse, T. (1994). Hyperlipoproteinaemia associated with atherosclerosis and cutaneous xanthomatosis in a cat. Vet Q 16, 199-202.

Witztum, J.L., and Steinberg, D. (1991). Role of oxidized low density lipoprotein in atherogenesis. J Clin Invest 88, 1785-1792.

Worthley, S.G., Helft, G., Fuster, V., Zaman, A.G., Fayad, Z.A., Fallon, J.T., and Badimon, J.J. (2000). Serial in vivo MRI documents arterial remodeling in experimental atherosclerosis. Circulation 101, 586-589.

Yanni, A.E., Yatzidis, H.A., Kavantzas, N.G., Agapitos, E.V., Perrea, D.N., and Karayannacos, P.E. (2003). Dietary L-aspartate and Lglutamate inhibit fatty streak initiation in cholesterol-fed rabbit. Nutr Metab Cardiovasc Dis 13, 80-86.

Zhang, S.H., Reddick, R.L., Piedrahita, J.A., and Maeda, N. (1992). Spontaneous hypercholesterolemia and arterial lesions in mice lacking apolipoprotein E. Science 258, 468-471. 